\title{
Research Paper: Studying Factors Affecting Quality of Life Using Multilevel Models: A Case Study in Rural Areas of crossuark Kangavar County
}

\author{
Hassan Ali Faraji Sabokbar'1, Mohammad Najarzadeh², ${ }^{2 *}$ Zabihullah Torabi ${ }^{3}$, Ahmad Malakan ${ }^{3}$ \\ 1. Associate Professor, Department of Human Geography, Faculty of Geography, University of Tehran, Tehran, Iran \\ 2. Assistant Professor, Department of Tourism Management, Faculty of Tourism, Semnan University, Semnan, Iran. \\ 3. PhD Student, Department of Human Geography, Faculty of Geography, University of Tehran, Tehran, Iran.
}

\begin{tabular}{|c|c|}
\hline $\begin{array}{l}\text { Use your device to scan } \\
\text { and read the article online }\end{array}$ & citation: Faraji Sabokbar, H. A., Najarzadeh, M., Torabi, Z., \& Malakan, A. (2017). Studying Factors Affecting Quality of \\
\hline 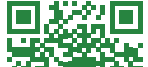 & $\begin{array}{l}\text { Life Using Multilevel Models: A Case Study in Rural Areas of Kangavar County. Journal of Sustainable Rural Development, } \\
\text { 1(1), 5-14. https://doi.org/10.18869/nrip.jsrd.1.1.3 }\end{array}$ \\
\hline 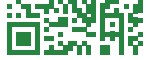 & doi : https://doi.org/10.18869/nrip.jsrd.1.1.3 \\
\hline
\end{tabular}

Article info:

Received: 14 Dec. 2016

Accepted: 13 Mar. 2017

Keywords:

Quality of life, Multilevel models, Rural areas of Kangavar

\begin{abstract}
Purpose: Quality of life is a broad concept, which its importance is increasingly growing. This concept in general term is used to describe how humans meet their needs or the extent to which individuals and communities are satisfied with the realm of life. Because resource are always limited at all levels of planning, it must be based on the efficient use of resources. Therefore, all available rural resources and their relationships at various levels should be identified. That is because one factor or cause from a higher level as a modifier variable has an impact on the relationship of two dependent variable at a lower level and would strengthen or weaken this relationship.
\end{abstract}

Methods:Therefore, in this research factors affecting the "quality of life" were studied in rural areas of Kangavr City with an emphasis on location and in the form of multi-level (three levels) factors. Data structure is hierarchical and has common features in every level, in a way that 250 observations were classified in 76 villages and 5 rural districts.

Results: The results show that individual factors affect the performance of higher-level variables i.e., village administration. And these two levels have an impact on the higher-level variables like the population density and so on.

Conclusion: Finally, the effects of villages and rural districts are significant, and have a significant effect on the predicted relationships.

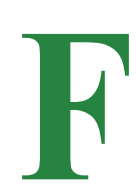

\section{Introduction}

or centuries, people naturally pursued a good life and in this regard, tried to make maximum use of their talents and capacities to improve their living conditions (Glyn Sharif Dini \& Hasanzade, 2011: 2). Therefore, since the emergence of early human societies, men tried to take control of their environment and man-made world in response to the their most basic natural and innate needs (Greco, Skordis-Worrall, Mkandawire, \& Mills, 2015). This control has been reflected in the form of discipline, pattern, and the man-made environment (Anabestani, Rosta, Mohamadi, \& Rafiieyan, 2015: 86). However,

* Corresponding Author:

Mohammad Najarzadeh, PhD

Address: Department of Tourism Management, Faculty of Tourism, Semnan University, Semnan, Iran.

Tel: +98 (23) 33323088

E-mail: mnajjarzadeh@semnan.ac.ir 
the planning had at first a unidirectional and economic perspective, and these shortcomings led to the attention to "quality of life" in recent years (Change the attitude from the one-dimensional development towards multidimensional and qualitative development) (Hosseini \& Bagherian, 2014: 56). Despite the abundance of goods, products and facilities of material life, most industrially-advanced countries face with the big challenges in terms of "quality of life" issues, such as psychological aspects of human society, ecology, and sociology. Because mere physical-functional approach to the city and ignoring values and social goals will cast doubts over the philosophy of cities which are places to live (Moosavi, Hasani, \& Manoochehri Miyandoab, 2013: 198). Therefore, development planners have highlighted priority goals of social development and proportion of the needs of service quality to people's living conditions (Mudey, Ambekar, Goyal, Agarekar, \& Wagh, 2011: 32).

Following the latest developments in industry, the necessity of "quality of life" with a focus on community development was introduced to improve social conditions (Fazelniya, 2015). "Quality of life" studies in monitoring general policymaking and social measures, especially in a society, could be considered as the most general objective of sustainable development, including economic, social, and environmental dimensions to improve the policy, activity, and life for different groups of society and the people (Brown, Hatton, \& Emerson, 2013: 316).

To the extent that in some research, "quality of life" is expressed as an interdisciplinary topic with different dimensions (Ülengin, Ülengin, \& Güvenç, 2001: 342) like material and spiritual facilities, including health, environment, laws, equality, employment, and family (Van Kamp, Leidelmeijer, Marsman, \& De Hollander, 2003: 7), which can demonstrate satisfaction of the spiritual, psychological, and material levels of society needs (Pal \& Kumar, 2005). Hence, it can be said that following the increasing decline of the quality of the human environment, environmental degradation, widespread pollution, class gap (which its obvious presentation is in form of spatial gap), "quality of life" is mentioned as the main problem in the optimization of human living environment (Faraji, 2010: 21).

As it was mentioned, there are many factors influencing upgrading or downgrading "quality of life". For example, Schaeffer et al. offered a model in 2000 consisted of three realms of social, environmental, and economic (van Kamp et al., 2003). According to this model, it can be deduced that "quality of life" is greatly influenced by time and space and its components and factors are different due to the time period and geographical location (Zan- ganeh Shahrak, 2014: 177). In other words, investigating "quality of life" in rural areas is associated with various factors, including individual factors such as low levels of social capital (participation and cohesion, etc.); Social factors such as lack of job opportunities, limited career choices, low facilities and income, social services, poor health; and locational factors such as limitation of access to water resources, soil, production level, and so on, which are causes of low "quality of life" and decreased life satisfaction of villagers (Grgic, Žimbrek, Tratnik, Markovina, \& Juracak, 2010: 658). So far valuable studies have been made in the area of "quality of life", however, there is a gap regarding multi-level investigation of the factors affecting "quality of life" with an emphasis on location. In this article, the various levels, including individual and locational levels are considered separately.

\section{Literature Review}

For many years, the issue of "quality of life" and its promotion has drawn the attention of planners in different areas, including urban and rural (Parvin, Kalantari, \& Davoodi, 2015: 1; Wish, 1986: 95). In the 20th century, lots of discussions have been made regarding the concept of "quality of life" in social and management studies, especially in low-income classes of people with the poor facilities (Faraji Sabokbar, Sadeghloo, \& Sojasi Ghidari, 2006: 28). However, in the last decade, regarding the complexity of today's world, the concept of "quality of life" has gained more attention (Parvin et al., 2015: 1).

Paying scientific attention to the concept of "quality of life" dates back to the industrial revolution and increasing growth of the process of social differentiation in industrial societies (Fazelniya, 2015), which has been mentioned as a reaction against the domination of economic indicators in the process of policy making in early 1960s (Veenhoven, 2007: 1). Therefore, since early 1990s, issues related to social development such as social capital, social cohesion, etc. entered the literature of development and with the UN emphasize, "social well-being" and "quality of life" were placed at the top of development goals, bringing with themselves the reduction of poverty and environmental degradation, longevity and, generally improvement of the "quality of life" (Ghafari, Karimi, \& Nozari, 2012: 108). Thus the concept of "quality of life" was put forward along with the increase in population, complex problems and issues, and attention to "quality of life" seemed to be more important than ever (Khorasgani \& Kianpoor, 2007: 67).

This is a complex and multi-dimensional concept which is influenced by factors such as time, place, the 
position of the individual in the cultural context and the value system that he or she lives in. It is in relation to the objectives and standards (Nilsson, 2006: 121), including material issues (standard living facilities) and nonmaterial issues (personal experiences and individuals) (Dajian \& Rogers, 2006: 15). It naturally has different meanings from different groups' points of views (Najafi Kani, Khajeh Shahkohi, Mahdavi, 2014: 212; Rezvani, Mansourian, Ahmadi, 2011: 5). This is a concept, which at first gained serious consideration regarding quality of urban life in developed and industrialized cities and countries from 1970s onwards. Different disciplines such as sociology and psychology tried to define the concepts and components of "quality of life" (Kokabee, 2005: 21) to study different geographical areas, such as cities, states and nations on the basis of these indicators (Ghorbani, Khakpoor, \& Mafi, 2008: 4).

Since human being primarily pursues welfare and always tries to increase his or her enjoyment level of welfare. "Quality of life" can be defined as people's understanding about their position in life, taking into account cultural content and values in which they live and in relation to their objectives, standards and concerns (Huang et al., 2015). Hence it can be said that "quality of life" can have different meanings for different people and many factors, including hereditary characteristics and income, family, community, geographic factors (soil and water available), as well as historical factors will be important and effective defining the "quality of life" (Massam, 2002: 192).

As it was already mentioned, "quality of life" is the main subject of many investigations in the different scientific fields, but a comprehensive and general definition for this concept still remains a problem, because many researchers believed that "quality of life" is a multi-faceted and relative concept that is affected by time, place (Zarrabi, Razmpoori, Alizadeh Asl, \& Noori, 2013: 21), cultural and social context, and the individual's value system (Ghafari et al., 2012: 114), ranging from indicators such as feeding and clothing habits to health care, social environment and the physical surroundings (Barimani, Jafari, \& Balochi, 2012: 43). Therefore, "quality of life" lacks standard and homogeneous indicators, but is defined in different conditions of societies (Ahmadi, Mirfardi, \& Ebtekari, 2013: 140).

However, some people define it as the viability of a region and some define it as the general welfare, social well-being, happiness and satisfaction (Faraji Sabokbar et al., 2006: 29). Cutter also defines it as person's satisfaction from life and his or her surroundings and Malmen defines it as dynamic interaction between a given person, community, and residence (Marsousi \& Lajevardy, 2014: 71). Others know it as a good feeling that is defined as a combination of factors related to the sense of place or local identity such as readability, collective memory and a sense of history, i.e., the emotional response between our psyche and form of the environment (Hosseini \& Bagherian, 2014: 60).

In general, there are different approaches towards "quality of life" and in this research agency-oriented, structureoriented, and ecology approaches are emphasized which we will discuss them one by one. Agency-oriented or the individualistic approach is based on individualism methodology, which disregard the society as a whole, but as the sum of the individuals (Ziari, Pilevar, \& Ahmadi, 2015: 23).

This approach states that although meta-individual factors are effective, it reduces these factors to individualistic ones and emphasizes the agency's role in shaping that process. In other words, this approach emphasizes on individual agents and his or her actions and thoughts over the structural, social, and environmental conditions. Out of the main agency-oriented approaches, we can point to desirability approach; need-driven approaches such as basic needs, human needs; and capability approach. In these approaches, individual factors such as nutrition, affordable housing, education, employment, health, partnership, trust, security and commitment are effective (Haghighatian, 2014: 84). Accordingly, Scott believed that "quality of life" depends on the capabilities within the person and individual aspects (Zhao, 2004: 13), which provides the foundation for growth and self-realization (Bostani, Ebtekari, \& Mohammadpur, 2012: 173).

Structure-oriented approach compared to agency-oriented approach has two distinctive aspects, the first of which offers full and comprehensive concept for "quality of life", which encompasses all effective areas in improving "quality of life" (Fattahi, 2010: 64) and the second one considers the subject as a whole, because the "quality of life" develops out of the person-environment interaction (social, economic, natural, etc.) (Najafi, Ahdnejad, Daviran, 2015: 79). In fact, this approach offers a systematic framework considering "quality of life" beyond the needs and in connection with the processes meaning that "quality of life" in its true sense cannot be separated from its relations (Fattahi, 2010: 64).

In this approach, "quality of life" is a multidimensional construct, which contains material, emotional, psychological, social and behavioral realms (Yazdani, Haghighatian, Keshav a rz, 2012: 165-166). The ecological approach emphasizes the distribution of social activities (quality of life) on space and time. Ecologists 
pay attention to two topics which are very important in the analysis of "quality of life". First, how distribution activities in space and time and environment will hinder the achievement of goals. Second, how this distribution has an effect on social experience of those who are exposed to it (Mokhtari \& Nazari, 2010: 105).

Therefore, "quality of life" has been the focus of human life from the very beginning, but in recent decades, it was felt necessary more than ever for reasons such as population growth and industrialization. A concept that many factors such as personal and social features, time and space are effective on it. Hence in order to achieve this important goal, it is better to have an integrated and systemic attitude to consider all factors affecting it.

\section{Multilevel models}

Although multilevel models were informally used in the past, they were officially introduced for the first time by Goldstein in 1989 for modeling of linear data. Then, wide range applications of such models helped its spread by various researchers in such fields as medicine, social sciences, and agriculture (Erez \& Gati, 2004). The integration of these models with other statistical models leads to new achievements in modeling different phenomena. One can imagine that according to the needs of different sciences, various notations for the analysis of multilevel models were introduced, but Goldstein notation was used in the present study (Snijders, 2011). To continue the discussion, a number of conventional notations of multilevel models are mentioned below.

Let $\mathrm{N}$ person are grouped within the $\mathrm{J}$ group, so that $\mathrm{n}_{\mathrm{j}}$ is the member of the $\mathrm{J}$ group. In addition, assume that for $\mathrm{J}$ group, we want to perform regression for response $y_{j}$ (continuous) variable on $P$ set of continuous variables stored in the $X_{j}$ matrix. Thus, for the $j_{t h}$ group, we write:

$$
\text { (1) } Y_{j}=X_{j} \beta_{j}+r_{j}
$$

$j=1, \ldots . ., J$

, where $Y_{j}$ vector is $n_{j}$-dimensional, $x_{j}$ is a matrix with $n_{j} \times p$ dimensions, $\beta_{j}$ is a $p$-dimensional vector and $r_{j}$ is measurement error and a random variable, so that:

(2) $\mathrm{r}_{\mathrm{j}} \sim \mathrm{N}\left(0_{\mathrm{nj}}, \sigma^{2} \mathrm{I}_{\mathrm{nj}}\right)$

, where $\mathrm{I}_{\mathrm{p}}$ is the P-dimensional identity matrix and a-dimensional vector of zeros. In the literature of multilevel models, model (1) with the assumption of (2) refers to the first level models. Bi-level models will take shape as a ran- dom variable considering $\beta_{\mathrm{j}}$ in the model (1). A special condition of a two-level model is that $\beta_{\mathrm{j}}$ is modeled as follows:

$$
\text { (3) } \beta_{\mathrm{j}}=\mathrm{w}_{\mathrm{j}} \gamma+\mathrm{uj}
$$

, where $\mathrm{w}_{\mathrm{j}}$ is the matrix of explanatory variables at the level of $\mathrm{j}^{\text {th }}$ group, $\gamma$ is a vector of constant coefficient and $u_{j}$ is error vector and has a normal distribution with zero mean and $\mathrm{T}$ variance; meaning that $\mathrm{u}_{\mathrm{j}} \sim \mathrm{N}(0, \mathrm{~T})$. Therefore, $\beta_{\mathrm{j}}$ can be considered as a random variable with a normal distribution with a mean of $\mathrm{W}_{\mathrm{j}} \gamma$ and $\mathrm{T}$ variance.

The combination of first and second level formula of bi-level model Equations 1 and 3 is as follows:

(4) $Y_{j}=X_{j} W_{j} \gamma+X_{j} u_{j}+r_{j}$

$\mathrm{i}=1, \ldots ., \mathrm{J}$.

Thus, $\mathrm{Y}_{\mathrm{j}}$ is normally distributed with an average of $\mathrm{X}_{\mathrm{j}} \mathrm{W}_{\mathrm{j}} \gamma$ and variance of $\mathrm{X}_{\mathrm{j}} \mathrm{TX}_{\mathrm{j}}^{\prime}+\sigma^{2} \mathrm{I}_{\mathrm{nj}}$. According to $4, \mathrm{Y}_{\mathrm{j}}$ is modelled based on both fixed effects of $\gamma$ and random effects of $u_{j}$ and $r_{j}$. That is why, these models are also called mixed models. Generally, multilevel models are included in three distinct classes: the simplest model is an intercept model without the presence of independent random variables (variance component model).

The second model is a model with random intercept model and the presence of independent variables. The third model which is more complex than the other two models is an intercept model with a random slope. It is clear that a combination of different types of such models will be also available when there are a large number of explanatory variables in the present model. For example, the following equation is an intercept model and two-level random slope for response variable $y$ with the explanatory variable $\mathrm{x}$ at the first level and explanatory variable of $\mathrm{w}$ for explaining variable response of the second level or coefficients in the second level:

The first level

(5) $\mathrm{y}_{\mathrm{ij}=} \beta_{0 \mathrm{j}}+\beta_{1 \mathrm{j}} \mathrm{x}_{\mathrm{ij}}+\varepsilon_{\mathrm{ij}}$

$\mathrm{i}=1, \ldots . \mathrm{j}$

$\mathrm{j}=1, \ldots, \mathrm{j}$

The second level

(6) $\beta_{0 \mathrm{j}}=\mathrm{y}_{00}+\mathrm{y}_{01} \mathrm{w}_{\mathrm{j}}+\mathrm{u}_{0 \mathrm{j}}$

$\beta_{0 \mathrm{j}}=\mathrm{y}_{10}+\mathrm{y}_{11} \mathrm{w}_{\mathrm{j}}+\mathrm{u}_{1 \mathrm{j}}$ 


\begin{tabular}{|c|c|c|c|c|}
\hline \multirow{2}{*}{\begin{tabular}{c} 
Factors affecting improvement of qual- $\begin{array}{c}\text { Level 1 } \\
\text { ity of life }\end{array}$ \\
\cline { 2 - 5 }
\end{tabular}} & Level 2 & $\begin{array}{c}\text { Village manage- } \\
\text { ment function }\end{array}$ & $\begin{array}{c}\text { Access to the } \\
\text { capital }\end{array}$ & $\begin{array}{c}\text { Access to ser- } \\
\text { vices }\end{array}$ \\
\cline { 2 - 5 } & Level 3 & $\begin{array}{c}\text { Area of rural } \\
\text { district }\end{array}$ & $\begin{array}{c}\text { Population of } \\
\text { rural district }\end{array}$ & $\begin{array}{c}\text { Density of rural } \\
\text { district }\end{array}$ \\
\hline
\end{tabular}

Figure 1. Conceptual research model

๑ JSRD

How to present the Equation 5 not only shows us all dependent variables, but also clearly indicates the nature of the multilevel model. In addition, in Equation 5, separating the first and second levels is clearly specified; therefore, the first level represents a simple linear regression and the second level shows how level one parameters are associated with the second level variables. To estimate model parameters, a method of maximum likelihood, repeated GLS, and GLS bound repetitive can be used (Sobhanifar \& Kharazian Akhavan, 2012). In this model, considering model coefficients variable instead of assuming them constant in a one-level models, interactive effects of macrolevel variables, and the micro-level variables are considered and the bias parameter estimations have improved greatly (Jamali, 2013: 100). Also multilevel models are to analyze the complex patterns and the nested variables with focusing on structure (Baneshi et al., 2013: 198).

\section{Methodology}

In this study, we tried to assess the effective factors on the "quality of life" using HLM multilevel software.
The data used in this article were collected using selfdesigned questionnaire, interviews, and available statistics. Based on the study model, the obtained data were grouped in three sections of rural districts, villages, and people (individuals). In this way, people in each village formed the data in the first level, villages in a rural district formed the second level data and all rural districts formed the third level data. The number of participants at the third level was 250, the number of rural districts under study in the second level was 76 and the number of rural districts in the third level was 5.

In the third level, a questionnaire was prepared in the form of 5-point Likert-type scale. These questionnaires have been completed through interviews with the heads of families. Accordingly, for each level, variables are defined as follows: social capital has been considered as an independent variable and quality of life as the dependent variable in level one; at the second level, variables regarding performance of rural districts, accessing to services and the distance from the city center have been considered; and in the third

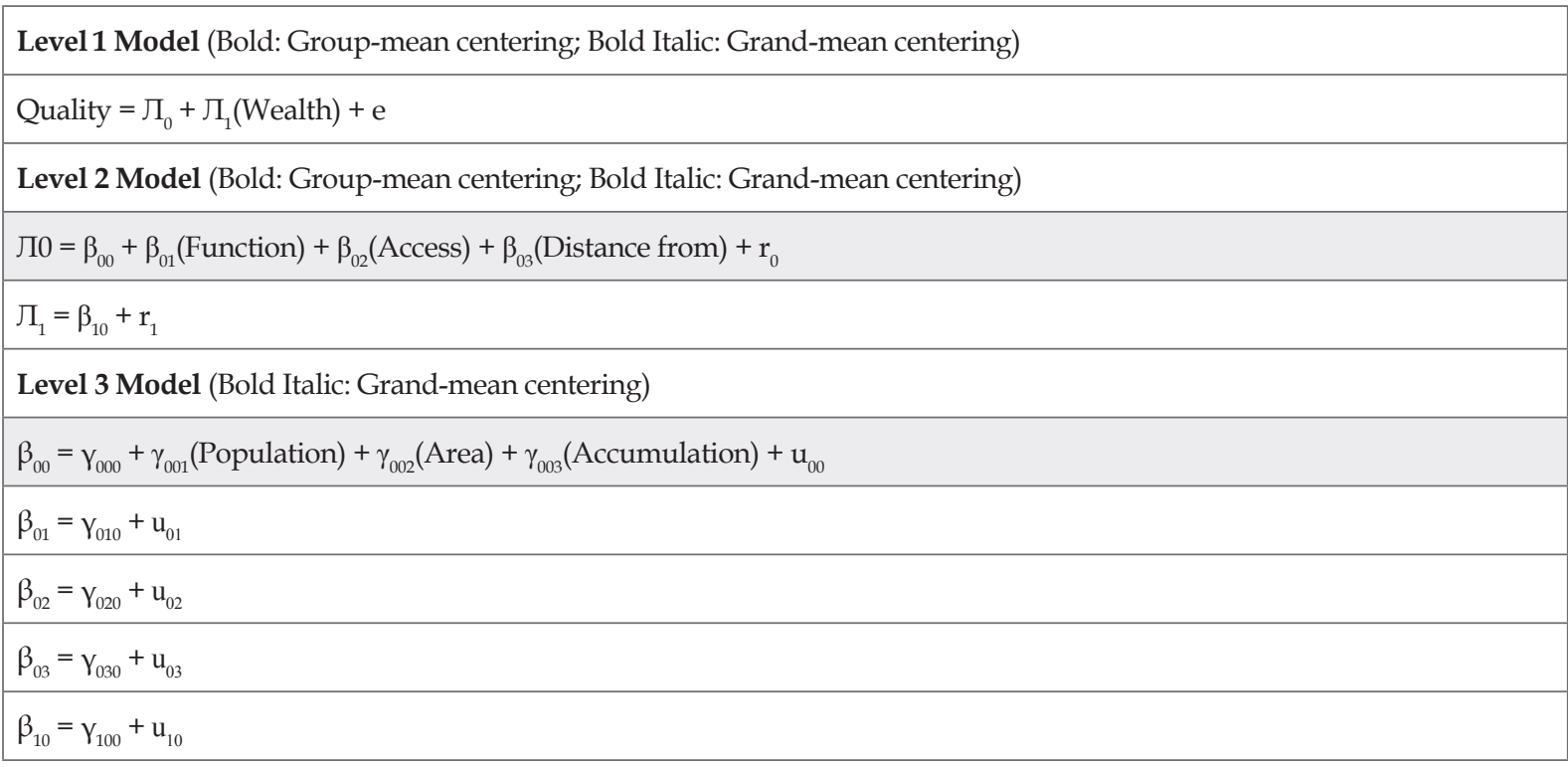

Quality $=\gamma_{000}+\gamma 001+$ Population $+\gamma_{002}+$ Area $+\gamma_{003}+$ Accumulation $+\gamma_{010}+$ Function $+\gamma_{020}+$ Access $+\gamma_{030}+$ Distance from + $\gamma_{040}+$ Wealth $+\mathrm{r}_{0}+\mathrm{u}_{00}+\mathrm{e}$

Figure 2. Predicted research model 
Table 1. Estimating the causal effect of the study variables

\begin{tabular}{cc}
\hline Variance & Value \\
\hline First level & 48.19 \\
Second level & 144.57 \\
Third level & 97.83 \\
\hline
\end{tabular}

Table 2. The reliability coefficients (Intraclass correlation)

\begin{tabular}{cc}
\hline Between Group Correlation Coefficient & Value \\
\hline First and second level & 0.75 \\
Second and third level & 0.67 \\
\hline
\end{tabular}

JSRD

level, population, rural district area and population density have been studied as variables of this level. On this basis, the research model is considered at three levels as follows (Figure 1). The predicted research model (Figure 2) separated by level is as follows:

The results of this model are based on output in the form of random and fixed effects which will be analyzed separately. Estimation of random effects is presented in the form of variances in the first, second, and third level, which include (Table 1):

In order to investigate positive impact groupings, the amount of reliability provided in software was used. In other words, this reliability is Intraclass Correlation Coefficient (ICC) which would indicate more positive effects of groups, if it was closer to 1 (Table 2). That is to say, this coefficient shows the variation between groups compared to the total variation (Between Group Variance+Error Variance). If the error variance is large (first level), the mentioned model will have poor reli- ability. Considering the above explanation, the value of this coefficient for both groups (village and rural districts) is as follows:

Higher values of these coefficients show positive effects of considering the effects of village and rural districts groupings. In other words, effect of village and rural districts are statistically significant (Table 3).

\section{Findings}

Considering 95\% confidence level, the significance level for all parameters was less than 0.05 , and therefore, there is a significant relationship between research variables. In other words, all independent variables had significant impact on the "quality of life" variable at all three levels.

Based on the three-level model (Individual, village, and rural district), the effects of independent variables on the "quality of life" variable were assessed using

Table 3. Estimated parameters of the model

\begin{tabular}{|c|c|c|c|c|c|}
\hline Fixed Effect & Coefficient & Error & T-Statistics & df & P-Value \\
\hline \multicolumn{6}{|c|}{$\begin{array}{l}\text { For Intercept 1, P0 } \\
\text { For Intercept 2, B00 }\end{array}$} \\
\hline Intercept 3, G000 & -5.4304 & 2.5345 & -2.1425 & 1 & 0.0328 \\
\hline Population, G001 & 0.2591 & 0.1133 & 2.2876 & 1 & 0.0037 \\
\hline Area, G002 & 2.9507 & 1.0136 & 2.9113 & 1 & 0.0008 \\
\hline Density, G003 & 1.6459 & 0.1899 & 8.6665 & 1 & 0.0000 \\
\hline \multicolumn{6}{|c|}{$\begin{array}{l}\text { For Capital Slope, P1 } \\
\text { For Intercept 2, B10 }\end{array}$} \\
\hline Intercept 3, G100 & 1.7423 & 0.2974 & 5.8590 & 245 & 0.000 \\
\hline
\end{tabular}


maximum likelihood method. Since there is a correlation between the views of people in the rural districts (independence of the different villages) and also solidarity in rural districts at a higher level, regression model could not be used. Because one of the assumptions of the regression model is independent observations. Due to the hierarchical structure of observations, conventional linear models cannot be used. Therefore, one of the best models which covers this hierarchical structure and the intraclass correlation are multilevel models. Such models are estimated at three levels. The first level includes estimating the between units model, the second level is an estimation between villages and the third level is estimation between the rural districts.

Interpretation of such models is the same as regression models and the effects of these levels will be discussed separately. As it was observed in interpretation of random effects, the effects of villages and rural districts are significant. In other words, people's belonging to different villages and rural districts has a significant effect on anticipated relations (effect of independent variables on the dependent variable). This means that this effect is different in various villages and districts. The intercept value has been estimated as -5.43 which indicates that if all variables had 0 values, the "quality of life" would have a negative value which is not desirable at all. The impact of the population on the quality is 0.25 , this means that by ignoring the rest of variables with increase of one unit of the population, 0.25 will be added on "quality of life" and vice versa.

Also with increase of one unit to area, 2.95 unit will be added to the "quality of life" and vice versa. Density has also a direct impact on the "quality of life", i.e., by reducing one unit from density, 1.65 unit is reduced from "quality of life" and vice versa. It seems that the least effect on the "quality of life" belongs to the performance of administration in the villages, because its impact on the "quality of life" is estimated to be 0.0302 .

Also, distance from the center and finally social capital (first level) have a direct effect on the "quality of life", which with an increase of one unit in them, 3.36, 2.36, and 1.74 unit will be added to the "quality of life", respectively. But it should be noted in the interpretation that parameters of population, area, and density were at the third level and vary from one rural district to other rural district. The performance parameter estimation, access, and distance from the center are on the second level that shows the effectiveness of the village effect on this three estimations, i.e. these three variables are changing from village to village and finally estimating social capital is not affected by the villages and rural districts.

\section{Discussion}

For many years, the issue of "quality of life" and its promotion has drawn the attention of planners in different areas, including urban and rural (Parvin et al., 2015: 1; Wish, 1986: 95). However, in the last decade, regarding the complexity of living, increasing population, and providing optimal services, "quality of life" has gained increasing importance. Therefore, this concept is complex and multi-dimensional and is influenced by factors such as time, location, position of individual in his or her value system and cultural context in relation to the objectives and standards, ranging from the material issues (standards and living facilities) and non-material ones (personal experiences and perceptions).

In this regard, identifying factors affecting "quality of life" is among the most important planning stages for regions, which is a key factor in the provision of services. Thus, planners used many models for achieving this goal. In this regard, multilevel models provide us a clearer understanding of the factors affecting the "quality of life", because on one hand, the coefficients of standard error in single-level models have been underestimated.

This sometimes turn insignificant variables in bi-level models to significant variables in single-level models or variables that are insignificant in the three-level models, turn into significant in bi-level models. On the other hand, the multilevel models involve geographical factors besides individual and social factors. Accordingly in this study, different individuals, social and geographical levels of "quality of life" were assessed. The results obtained show that G00 parameters are acceptable at the level of $5 \%$ error, meaning the effect of the first-, second- and third-level variables and regression coefficient of the first level on the second level and the effect of first and second level on the third level. Finally, the effect of G001, G002, and G003 (The third level variables) on the "quality of life" at the level of 5\% error represent a significant correlation between them and finally their influence on the "quality of life" is acceptable.

Furthermore, for every unit increase in area (about one kilometer), density (equivalent to square meter) and population (individual), "quality of life" improves 2.95 , $1.64,0.25$ units, respectively. In other words, the if first level of the individual factors (social capital) increases the performance of higher-level variables like villages administration and provision of better service improves and these two levels will affect the higher-level variables, including population density, etc. In this regard, Ahmadi et al. (2013), in their study show that dimensions of so- 
cial capital has a decisive role in improving the "quality of life". Study by Azimi (2013) shows that trust plays a decisive role in improving the "quality of life", or study by Darban et al. (2012) shows that social and physical factors play an effective role in improving the "quality of life". Our study is also in line with previous studies, but due to the hierarchical structure and intraclass correlation the biased coefficients of the variables are resolved.

\section{Acknowledgements}

This research did not receive any specific grant from funding agencies in the public, commercial, or not-forprofit sectors.

\section{Conflict of Interest}

The authors declared no conflict of interests.

\section{References}

Ahmadi, S., Mirfardi A., \& Ebtekari M. H. (2013). [The social capital impact on quality of life in Yasouj (Persian)]. Journal of socio-cultural strategy, 2(6), 135-159.

Anabestani, A., Rosta, M., Mohamadi, S. A., \& Rafiieyan, S, (2015). [Spatial analysis of the factors affecting the quality of life in rural settlements (Persian)]. Regional Planning, 5(18), 8599.

Azimi, J. (2013). [Analysis of good narrative verdict in rural (Case study: the villages of Mazandaran) (Persian)] (PhD dissertation). Tehran: Tarbiat Modares University.

Baneshi M. R., Rezaei, M., Shahroudi, S., Zolala F., Okhovati M., \& Haghdoost, A. A. (2014). [The application of multilevel linear models and generalized estimating equations to evaluate the quality of professors' teaching in various semesters (Persian)]. Studies in Development of Medical Education. 11(2), 196-204.

Barimani, F., Jafari, M., \& Balochi, O. (2012). [Measure and analysis of quality of life in rural areas (Case study: Mahban District, Nikshahr city (Persian)]. Journal of Geographical Vision in Human Studies, 8(23), 41-54.

Bostani, D., Ebtekari, M. H., \& Mohammadpur, A. (2012). [Assessment of quality life index in rural regions (Persian)]. Journal of Sociocultural Strategy, 1(4), 167-196.

Brown, I., Hatton, C., \& Emerson, E. (2013). Quality of life indicators for individuals with intellectual disabilities: Extending current practice. Intellectual and Developmental Disabilities, 51(5), 316-32. doi:10.1352/1934-9556-51.5.316

Dajian, Z., \& Rogers, P. P. (2006). 2010 world expo and urban life quality in shanghai in terms of sustainable development. Chinese Journal of Population Resources and Environment, 4(1), 15-22. doi:10.1080/10042857.2006.10677445
Darban, A. A., Rezvani, M. R. (2012). [Explain the factors affecting rural governance in local government (Case study: Qazvin township) (Persian)]. Urban Management-Institute of Urban and Rural Management, 29, 179-97.

Erez, M., \& Gati, E. (2004). A dynamic, multi-level model of culture: from the micro level of the individual to the macro level of a global culture. Applied Psychology, 53(4), 583-98. doi: 10.1111/j.1464-0597.2004.00190.x

Faraji, M. (2010). [Analysis and planning to improve the quality of life in the study: Babolsar (Persian)] (Master's thesis). Tehran: Tehran Univresity.

Faraji Sabokbar H., Sadeghloo T, \& Sojasi Ghidari H. (2006) Measurement of life quality in rural regions: A case study of Aghbolagh Sub-district in Zanjan Province (Persian)]. Journal of Village and Development, 14(4), 27-48.

Fattahi, A. A. (2010). [Measuring quality of life in rural areas (Case study: Delfan Central Region (Persian)] [MSc. thesis]. Tehran: Tarbiat Modares University.

Fazelniya, G. (2015). [Evaluation and comparative of quality of life indicators in extended and nuclear families (Case study: the rural areas in Poshtab district of Zabol) (Persian)]. Journal of Rural Research, 5(4), 849-74.

Ghafari, Gh. R., Karimi A., \& Nozari H. (2012). [Trend study of quality of life in Iran (Persian)]. Quarterly of Social Studies and Research in Iran, 1(3), 107-134.

Ghorbani Z., Khakpoor, B., \& Mafi E. (2008). [Analysis of the spatial distribution of the quality of life in the Chalus City (Persian)]. Research and Urban Planning, 4(13), 1-18.

Glyn Sharif Dini, J., \& Hasanzade, D. (2011). Quality of life in informal settlements Tehran metropolis (Case Study: Islamabad). Paper presented at The $1^{\text {st }}$ Annual Conference of Architectural, Urban Planning and Urban Management, Yazd, Iran, 15 December 2015.

Greco G, Skordis-Worrall J, Mkandawire B, Mills A. (2015). What is a good life? Selecting capabilities to assess women's quality of life in rural Malawi. Social Science \& Medicine, 130, 69-78. doi: 10.1016/j.socscimed.2015.01.042

Grgic, I., Žimbrek, T., Tratnik, M., Markovina, J., \& Juracak, J. (2010).Quality of life in rural areas of Croatia: To stay or to leave?. African Journal of Agricultural Research, 5(8), 653-660. doi: 10.5897/AJAR10.613

Haghighatian, M. (2014). [Social factors affecting the quality of life of women in Isfahan (Persian)]. Journal of Iranian Social Development Studies. 6(2), 81-89.

Hosseini, S. H., Bagherian, Kh. (2014). [An analysis on constituent component of quality of life in Nowshahr (Persian)] Amayesh Journal. 27, 55-78.

Huang, Y., Zhong, X. N., Li, Q. Y., Xu, D., Zhang, X. L., Feng, C., et al. (2015). Health-related quality of life of the rural-China left-behind children or adolescents and influential factors: a cross-sectional study. Health and Quality of Life Outcomes, 13(1), 29. doi: 10.1186/s12955-015-0220-x

Jamali, E. (2013). [Multilevel models in the humanities (Case Study: Test takers throughout) (Persian)]. Educational measurement and evaluation studies, 3(4), 9-36. 
Khorasgani, A., \& Kianpoor M. (2007). [The proposed model for measuring quality of life (Case study: Esfahan) (Persian)]. Journal of Faculty of Literature and Humanities. 58-59, 67-108.

Kokabi, A. (2005). [Planning to enhance the quality of urban life, the central zone of Khorramabad (Persian)] [MSc. thesis]. Tehran: Tarbiat Modares University.

Marsousi, N., Lajevardy, S. A. (2014). The comparative study of the quality of urban life in Iran (Persian)]. Iranian Journal of Economic Research, 14(2), 69-95.

Massam, B. H. (2002). Quality of life: public planning and private living. Progress in Planning, 58(3), 141-227. doi:10.1016/ s0305-9006(02)00023-5

Mokhtari, M., \& Nazari, J. (2010). [Sociology of quality of life (Persian)]. Tehran: Jame'e Shenasan.

Moosavi, M, Hasani, M., Manoochehri Miyandoab, A. (2013). [The analysis of social capital and its impact on quality of life (Case study: Miyandoab) (Persian)]. Human Geography Research, 45(4), 197-200.

Mudey, A., Ambekar, S., Goyal, R. C., Agarekar, S., \& Wagh, V. V. (2011). Assessment of quality of life among rural and urban elderly population of Wardha District, Maharashtra, India. Ethno-Medicine, 5(2), 89-93.

Najafi, S., Ahdnejad, M., Daviran, I. (2015). [Assessment of the life quality in informal settlements of the cities (Case study: Islamabad district of Zanjan City) (Persian)]. Journal of Management System, 5(16), 75-90.

Najafi Kani, A. A., Khajeh Shahkohi A. R., Mahdavi, Sh. (2015). Assessment of development indicators in urban areas with an emphasis on quality of Life. Case study: Kashan City (Persian)]. Geographical Planning of Space Quarterly Journal, 5(16), 211-224.

Nilsson, J. (2006). Social capital and quality of life in old age: Results from a cross-sectional study in rural Bangladesh. Journal of Aging and Health, 18(3), 419-34. doi:10.1177/0898264306286198

Pal, A. K., \& Kumar, U. C. (2005). Quality of life concept for the evaluation of societal development of rural community in West Bangal, India. Asia-Pacific Journal of Rural Development, 15(2), 83-93.

Parvin, S., Kalantari, A., Davoudi, R. (2015). [Quality of life of social groups in Tehran (Persian)]. Danesh-e Shahr. 318, 251-265.

Rezvani, M. R., Mansourian, H., Ahmadi, F. (2011). Promoting villages to city and its role on improvement of quality of life of local resident (Case Study: Firozabad and Sahen Cities in Lorestan and Kordestan Provinces) (Persian)]. Journal of Rural Research. 1(1), 33-65.

Sobhanifar, Y. \& Kharazian Akhavan, M. (2012). Factor analysis, structural equation modeling and multilevel. Tehran: Imam Sadiq University Pub.

Snijders, T. A. (2011). Multilevel analysis. New York: Springer.

Ülengin, B., Ülengin, F., \& Güvenç, Ü. (2001). A multidimensional approach to urban quality of life: The case of Istanbul. European Journal of Operational Research, 130(2), 361-74. doi:10.1016/s0377-2217(00)00047-3
Van Kamp, I., Leidelmeijer, K., Marsman, G., \& de Hollander, A (2003). Urban environmental quality and human well-being. Landscape and Urban Planning, 65(1-2), 5-18. doi: 10.1016/ s0169-2046(02)00232-3

Veenhoven, R. (2007). Quality of life research. In C. D. Bryant, \& D. L. Peck (Eds.). $21^{\text {st }}$ century sociology: A Reference Handbook (pp. 54-62). Philadelphia: Sage Publications, Inc.

Wish, N. B. (1986). Are we really measuring the quality of life? Well-being has subjective dimensions, as well as objective ones. American Journal of Economics and Sociology, 45(1), 93-99. doi:10.1111/j.1536-7150.1986.tb01906.x

Yazdani, A., Haghighatian, M., Keshavarz, H. (2012). [Analysis of the quality of life of women with emotional divorce (Case study: Shahrekord) (Persian)]. Journal of Sociocultural Strategy, 2(6), 159-185

Zangene Shahraki, S. (2014). [Evaluation of the quality of life in informal settlements, Tehran Metropolitan (Case study: Islamabad Salehabad) (Persian)]. Human Geography Research Quarterly, 46(1), 177-196.

Zarrabi, A., Razmpoori, A. A., Alizadeh Asl, J., \& Noori, M. (2014). [Measuring and evaluating the quality of life index in medium cities (Case study: Yasuj City) (Persian)]. Spatial Planing, 4(3), 15-36.

Zhao, B. (2004). Perceptions of quality of life and use of human services by households: A model (PhD Dissertation). Lexington, Kentucky: University of Kentucky.

Ziari, K., Pilevar, A. A., \& Ahmadi, M. (2014). [Analysis of measure quality of life in new towns (A case study: New city of Binalud) (Persian)]. Geographical Planning of Space Quarterly Journal, 5(16), 19-36. 
